\title{
$\mathrm{PQRST}$ 파 특징 기반 신호의 분류를 이용한 심전도 \\ 압축 알고리즘 성능 평가
}

준회원 구 정 주

\section{Performance Evaluation of ECG Compression Algorithms using Classification of Signals based PQSRT Wave Features}

\author{
Jung-joo Koo*, Goang-seog Choi ${ }^{*{ }^{*}}$ Associate Members \\ 요 약
}

심전도의 압축은 시스템의 처리 속도를 높일 뿐만 아니라 신호의 전송량, 장기적인 기록 데이터 저장량을 줄 일 수 있다. 본 논문에서는 기존의 심전도 데이터의 손실 혹은 무 손실 압축 알고리즘에 대한 성능 평가가 엔지 니어의 관점에서 $\mathrm{PRD}$ (Percent RMS Difference)와 $\mathrm{CR}$ (Compression Ratio)을 측정하였다면 심전도를 진단하는 진단자의 관점에서 압축의 성능 평가에 대한 연구를 하였다. 일반적으로 심전도 데이터의 압축이 진단에 영향을 미치지 않게 하기위해서는 압축 후 복원된 PQRST파의 위치, 길이, 진폭, 파의 형태 등 진단에 필요한 것들이 손 상되어선 안 된다. 대표적인 심전도 압축 알고리즘 AZTEC은 기존의 성능평가에 그 효율성이 검증되었지만 진단 자의 관점에서 새로운 성능평가를 제시한다.

Key Words : 심전도, 심전도압축, 심전도압축 성능, $\mathrm{PRD}, \mathrm{CR}$

\section{ABSTRACT}

An ECG(Electrocardiogram) compression can increase the processing speed of system as well as reduce amount of signal transmission and data storage of long-term records. Whereas conventional performance evaluations of loss or lossless compression algorithms measure PRD(Percent RMS Difference) and $\mathrm{CR}$ (Compression Ratio) in the viewpoint of engineers, this paper focused on the performance evaluations of compression algorithms in the viewpoint of diagnostician who diagnosis ECG. Generally, for not effecting the diagnosis in the ECG compression, the position, length, amplitude and waveform of the restored signal of PQRST wave should not be damaged. AZTEC, a typical ECG compression algorithm, is validated its effectiveness in conventional performance evaluation. In this paper, we propose novel performance evaluation of AZTEC in the viewpoint of diagnostician.

\section{I. 서 론}

심전도(Electrocardiography, ECG)란 심장이 박동 할 때마다 심장 내에서 발생하는 전기적 활동
(Electrical Activity)을 기록한 것이다. 즉, 심장의 전기신호를 피부에 부착한 전극을 통해 그림으로 기록하는 것으로 심장에 대한 검사 중 가장 기본이 된다. 심전도 측정은 진단자의 주관적인 판단에 의

\footnotetext{
※ 이 논문은 2010학년도 조선대학교 학술연구비의 지원을 받아 연구되었음

* 조선대학교 정보통신공학과 SoC설계실습실 (go_mystar@naver.com),

** 조선대학교 정보통신공학과 (gschoigs@ chosun.ac.kr), ( ${ }^{\circ}$ : 교신저자)

논문번호 : KICS2012-02-095, 접수일자 : 2012년 2월 29일, 최종논문접수일자 : 2012년 4월 10일
} 
해 이루어지지만 궁극적인 목적은 심장의 이상 유 무를 판단하기 위한 것으로 신호의 대표적인 파형 $\mathrm{P}$ 파, $\mathrm{QRS}$ 군, $\mathrm{T}$ 파에 의해 측정되고 각 파형은 심장 의 심방과 심실 활동으로 특징지어진다. 파형의 모 양뿐만 아니라 간격(파를 포함한 거리)과 분절(파를 포함하지 않는 파와 파사이의 거리)은 심장의 상태 측정에 중요한 측정요소가 되고 그 외에도 많은 요 소들이 필요하다 ${ }^{[1]}$.

최근에 홀터 심전계의 개발과 실시간 데이터 전 송, 제한된 메모리용량으로 인해 임상정보(의학적 정보)보존의 요구아래 압축이 불가피하게 되었다. 즉, 시스템의 제한된 용량 ${ }^{[2]}$, 전송 대역폭 한계 ${ }^{[3]}$, 에너지 소비 감소를 위한 데이터 양 최소화 ${ }^{[4]}$ 를 보 완하기위해 압축은 필수적이다.

이러한 이유로 지난 30년간 심전도에 대한 많은 압축 알고리즘이 제안되었다. 알고리즘은 아래 표와 같이 구분할 수 있다.

표 1. 심전도 압축 알고리즘의 구분

Table. 1. Classification of ECG Compression Algorithm

\begin{tabular}{|c|c|c|}
\hline 직접압축방식 & $\begin{array}{c}\text { 변환식을 이용한 } \\
\text { 방식 }\end{array}$ & $\begin{array}{c}\text { 신호의 특징과 } \\
\text { 매개변수 추출방식 }\end{array}$ \\
\hline $\begin{array}{c}\mathrm{TP} \\
\text { (Turning Point) }\end{array}$ & Fourier descriptor & \multirow{4}{*}{$\begin{array}{l}\text { Linear Prediction } \\
\text { Method }^{[10]}\end{array}$} \\
\hline $\begin{array}{c}\text { AZTEC }^{[5]} \\
\text { (Amplitude Zone } \\
\text { Time Epoch } \\
\text { Coding) }\end{array}$ & $\begin{array}{c}\text { KLT }^{[7]} \\
\text { (Karhunen-Loeve } \\
\text { Transform) }\end{array}$ & \\
\hline $\begin{array}{c}\text { CORTES } \\
\text { (Coordinate } \\
\text { Reduction Time } \\
\text { Encoding) }\end{array}$ & $\begin{array}{c}\mathrm{DCT}^{[8]} \\
\text { (Discrete Cosine } \\
\text { Transform) }\end{array}$ & \\
\hline Fan 알고리즘 ${ }^{[6]}$ & $\begin{array}{c}\text { Wavelet } \\
\text { Transform }^{[9]}\end{array}$ & \\
\hline
\end{tabular}

심전도 압축의 중요한 문제점 중 하나는 오류에 대한 기준이 명확하지 않다는 점에 있다. 압축의 목 적은 복원된 신호에 대해 진단에 영향을 미치지 않 는 범위 내에서 관련이 없는 정보를 제거함에 있지 만 현재 압축에 대한 성능은 주로 $\mathrm{PRD}$ (Percent RMS Difference)와 CR(Compression Ratio)에 의해 평가되며 지금까지의 대표적인 압축 알고리즘 $\mathrm{AZTEC}$ 역시 이러한 성능에 의해 평가되고 있다. 하 지만 이러한 성능평가는 진단의 관점에서는 거의 관련성이 없고 간단한 수학적 백분율로 신호에 대
한 엔지니어의 관점으로 평가된다. 본 논문에서는 심전도를 진단하는 진단자의 관점에서 압축의 성능 평가에 대한 연구를 하고자 한다.

\section{II. 본 론}

\section{1. 관련 연구}

\subsection{1. 기존 성능평가의 문제점}

대부분의 심전도 압축 알고리즘은 PRD로 평가되 며 식(1)과 같이 나타난다.

$$
P R D=\sqrt{\frac{\sum_{n=1}^{L}(x(n)-\tilde{x}(n))^{2}}{\sum_{n=1}^{L} x^{2}(n)}} \times 100
$$

여기서, 은 압축하기 전 원래의 신호를, 은 압축 후 복원 된 신호를, 은 PRD가 계산되는 동안의 계 산범위를 나타낸다. 이때 원 신호와 복원된 신호의 차이점을 계산하기 위해 $\mathrm{SNR}$ (Signal-to-Noise Ratio)을 계산한다. SNR은 신호에 대한 잡음을 타 나내는 척도로, 신호전력을, 잡음전력을 이라 할 때 식 (2)과 같다.

$$
S N R=10 \log (S / N)
$$

여기서, 신호전력 는 원래의 신호를 의미하고, 잡 음전력 은 원래의 신호에서 복원된 신호의 차이 즉, 왜곡된 범위를 뜻한다. 따라서 $\mathrm{SNR}$ 은 식 (3)과 같이 나타낼 수 있다. 또한 식 (4)과 같이 PRD와의 관계가 성립된다. $\mathrm{PRD}$ 는 대체적으로 식 (5)에 나타 나는 압축률(CR, Compression Ratio)에 영향을 받 는다. 식 (5)에서 은 압축되기 전 원신호의 비트수, 은 압축된 신호의 총 비트수를 타나낸다.

$$
\begin{gathered}
S N R=10 \log \left(\frac{\sum_{n=1}^{L} x^{2}(n)}{\sum_{n=1}^{L}(x(n)-\tilde{x}(n))^{2}}\right) \\
S N R=-20 \log (0.01 P R D) \\
C R=\frac{N_{I N P}}{N_{\text {OUT }}}
\end{gathered}
$$


표 2는 $\mathrm{MIT} / \mathrm{BIH}$ 데이터베이스에 있는 압축 테 스트용 데이터 중 10 개를 선정하여 ZOI(Zero Order Interpolator)에 기초를 둔 손실 압축 알고리즘 $\mathrm{AZTEC}$ 에 대한 $\mathrm{PRD}$ 값을 계산한 값이다[11]. $\mathrm{MIT} / \mathrm{BIH}$ 데이터 베이스란 심전도 처리에 대한 연 구를 하고, 기법을 개발하여 그것에 대한 결과를 얻 고자 할 때 이를 일반화하여 많은 사람들에게 적용 하기 위해, 또한 개발된 기법이 기존의 기법들과 정 당하게 비교되기 위해서 동일한 데이터를 이용해야 하는데 이 때 사용되는 데이터를 모아둔 것이다. 최 근에는 PTB데이터베이스 또한 많이 사용하고 있는 추세이다.

표 2. 각 압축 비율과 $\mathrm{PRD}$ 의 결과

Table. 2. Results of each Compression Ratio and PRD

\begin{tabular}{|c|c|c|}
\hline & CR & PRD \\
\hline 08730_01.dat & 7.1 & $12.9 \%$ \\
\hline 12621_04.dat & 6.0 & $29.7 \%$ \\
\hline 12713_04.dat & 10.6 & $16.6 \%$ \\
\hline 11442_04.dat & 4.9 & $34.5 \%$ \\
\hline 11950_01.dat & 7.5 & $33.3 \%$ \\
\hline 11950_03.dat & 8.6 & $23.2 \%$ \\
\hline 12936_03.dat & 5.3 & $17.9 \%$ \\
\hline 12931_02.dat & 4.6 & $35.6 \%$ \\
\hline 12490_01.dat & 7.3 & $24.2 \%$ \\
\hline 12621_01.dat & 5.3 & $16.6 \%$ \\
\hline
\end{tabular}

수학적으로 보면 잡음의 계산은 타당성이 있어 보이지만 진단의 관점에서는 많은 문제가 발생한다. 심전도 신호의 주요 파형 $\mathrm{P}$ 파, $\mathrm{QRS}$ 군, $\mathrm{T}$ 파는 진단 에 있어서 각각의 중요성을 지니고 있고, 특히 상대 적으로 낮은 주파수를 갖는 $\mathrm{P}$ 파와 $\mathrm{T}$ 파 같은 경우 왜곡이 되더라도 $\mathrm{PRD}$ 수치에는 크게 영향을 끼치지 않는다. 또한 신호가 베이스라인을 기준으로 변동이 있을 경우 편차 값은 높아지고 $\mathrm{PRD}$ 값은 수치적으 로 낮아지는 문제점이 발생한다. 따라서 심전도 압 축에 대한 성능평가를 기존의 $\mathrm{PRD}$ 와 $\mathrm{CR}$ 을 사용하 는 것은 문제가 있다.

\subsection{2. 심전도의 각 파형과 파형간의 간격}

심장은 신경계의 도움 없이 율동적인 박동을 일 으키고 유지한다. 심장은 근육으로 구성된 펌프기관 으로 궁극적 목적은 신체 전 조직에 혈액을 공급하
고 조직이 필요로 하는 산소를 충분히 공급하는 것 이다. 심장은 4 개의 구역으로 나누어져 있으며 4 개 의 방 중 심방 상부에 위치해 심방중격(Interatrial Septum)으로 구분된 두 개의 방을 각각 우심방 (Right Atrium)과 좌심방(Left Atrium)이라고 한다. 또한 심장 하부에 위치하고 심실중격 (Interventricular Septum)으로 구분된 두 개의 구역 을 각각 우심실(Right Ventricle), 좌심실(Left Ventricle)이라 한다.

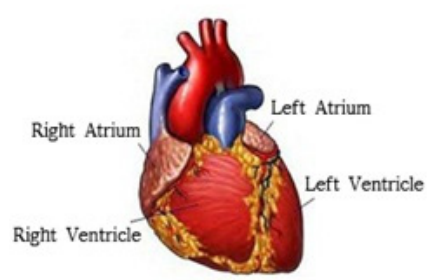

그림 1. 심장 구조

Fig. 1. Heart Structures

심장세포는 한 번에 심장 전 부위가 탈분극 되도 록 하기 위해 매우 빠른 속도로 주변에 있는 심장 세포로 전기 자극을 전도한다. 신체표면의 정해진 부위에 전극을 부착 후 전극을 다양하게 조합하여 심장의 전기적 활동을 기록한 것이 심전도이다. 기 본적으로 $\mathrm{P}$ 파, $\mathrm{QRS}$ 군, $\mathrm{T}$ 파가 기록되며 이를 분석 함으로써 비정상적인 전도 및 심방과 심실의 크기 변화, 심장 박동의 이상 유무 등을 밝히는데 사용된 다. 심전도의 진단은 진단자의 주관적인 판단 하에 이루어지지만 이를 위해서는 기본적인 파형 $\mathrm{P}$ 파, $\mathrm{QRS}$ 군, $\mathrm{T}$ 파 뿐만 아니라 파형간의 간격, 길이, 진 폭, 파 등의 형태가 필요하다. 심박동수 계산을 위 한 R파와 다음 R파사이의 간격(R-R Interval), 심장 의 양 심실 탈분극과 재 분극까지의 시간계산을 위 한 $\mathrm{QT}$ 간격(Q-T Interval, $\mathrm{QRS}$ 군 시작부터 $\mathrm{T}$ 파 끝 까지의 거리), 심방의 탈분극과 방실전도까지의 전 도를 위한 PR간격(P-R Interval, $\mathrm{P}$ 파 시작부터 $\mathrm{QRS}$ 군 시작까지의 거리)이 대표적이다.

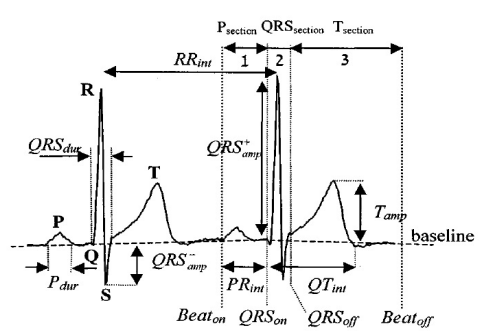

그림 2. $\mathrm{PQRST}$ 파형의 위치와 파형간의 간격

Fig 2. Location of the PQRST Waveform and Interval between Waveform 


\section{2. 제안하는 압축 알고리즘에 대한 성능평가}

\subsection{1. 곡률을 이용한 파형구분}

진단에 필요한 6가지 요소에 대한 각각의 왜곡 율을 계산하기 위해선 먼저 $\mathrm{P}$ 파, $\mathrm{QRS}$ 군, $\mathrm{T}$ 파 각각 의 시작과 끝을 구분 하고 극점을 찾아내야 한다. 심전도 파형은 $\mathrm{P}$ 파 $\mathrm{QTS}$ 군 $\mathrm{T}$ 파가 연속적인 형태로 나타나고 각 파형의 시작과 끝, 극값은 다른 정점에 비해 곡률(곡선위의 한 점이 일정한 속도로 이동할 때 이동방향에 따른 거리의 변화 율. 즉, 곡선 또는 곡면의 휨 정도)값이 크므로 이점을 이용하여 파형 을 구분하고 가우시안 함수를 사용하여 평활화 (Smoothed)작업을 거쳐 신호에 대한 잡음이 각 파 형의 시작점과 끝점에 영향을 끼치지 않게 한다 ${ }^{[11]}$. 심전도의 주요 파형인 $\mathrm{P}$ 파, $\mathrm{QRS}$ 군, $\mathrm{T}$ 파의 특징점 을 추출하기 위해서는 각 정점에서의 곡률의 크기 를 구하고 이들 중 큰 값을 선택한다. 평활화 작업 이 이루어지기전 신호를 $C(t)$ 라 할 때 $(t$ 는 곡선 위의 점의 시간 값 $)$ 가우시안 함수 $(g(t, \sigma))$ 를 사용 하여 평활화 된 신호를 식 (6)과 같이 나타낸다.

$$
C(t, \sigma)=(S(t, \sigma), V(t, \sigma))
$$

여기서, $s(t, \sigma)$ 는 $t$ 시간에 위치한 점의 표본 지 표 $s(t)$ 에 컨볼루션 한 값이고, $v(t, \sigma)$ 는 신호의 전위 값 $v(t)$ 에 가우시안 함수를 컨볼루션 한 값이 다. $\sigma$ 는 가우시안 함수의 평활 화 단계를 나타내며 이 값이 어느 정도 클수록 신호에서 각 파형의 시 작점과 끝점만 남게 된다. 평활 화 된 신호 $(C(t, \sigma))$ 로부터 시작점과 끝점은 다음과 같이 계 산한다.

$$
\begin{gathered}
k(t, \sigma)=\frac{S^{\prime \prime}(t, \sigma) V^{\prime}(t, \sigma)-S^{\prime}(t, \sigma) V^{\prime \prime}(t, \sigma)}{\left(S^{\prime}(t, \sigma)^{2}+V^{\prime}(t, \sigma)^{2}\right)^{3 / 2}} \\
S^{\prime}(t, \sigma)=\left(s(t) \otimes \frac{\partial}{\partial t} g(t, \sigma)\right) \\
S^{\prime \prime}(t, \sigma)=\left(s(t) \otimes \frac{\partial}{\partial t^{2}} g(t, \sigma)\right) \\
V^{\prime}(t, \sigma)=\left(v(t) \otimes \frac{\partial}{\partial t} g(t, \sigma)\right) \\
V^{\prime \prime}(t, \sigma)=\left(v(t) \otimes \frac{\partial^{2}}{\partial t^{2} g} g(t, \sigma)\right)
\end{gathered}
$$

계산된 값 중 가장 큰 값은 심전도에서 $\mathrm{R}$ 파형이 되고 식 (7)과 (8)을 적용하여 파형의 각 점에 대한 곡률 값을 계산한다. 곡률 중 일정한 값 보다 큰 값만을 취한다. 선택된 점은 각 파형의 시작점과 끝 점, 극점으로 선택된다.

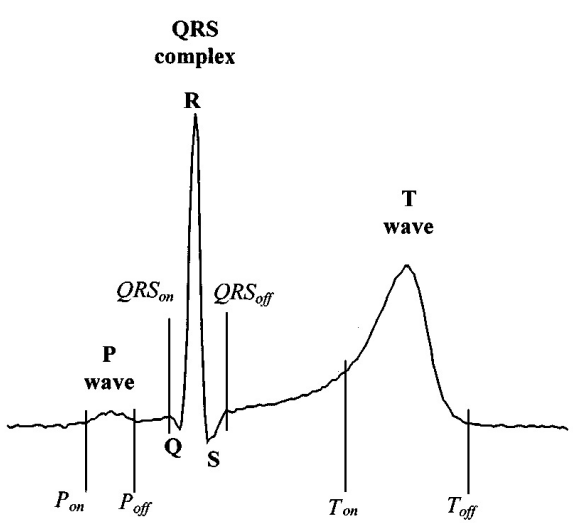

그림 3. 파형별 시작점과 끝점, 극점

Fig. 3. Waveform starting and ending points, Poles

\subsection{2. 각 파형에서의 왜곡율 계산}

심전도의 $\mathrm{P}$ 파, $\mathrm{QRS}$ 군, $\mathrm{T}$ 파의 구분이 이루어지 면 각 파형별로 위치, 길이, 진폭, 형태를 계산한다. 이때 심전도 신호를 2 차원 그래프로 나타냈을 때 시간을 나타내는 축을 $x$ 축, 신호의 전위 값을 나타 내는 축을 $y$ 축이라 한다.

각 파형의 위치, 길이, 진폭에 대한 왜곡율 계 산을 위해 파형별로 원 신호에 대한 시작점과 끝점 을 각각 $S_{O N}\left(S_{O N x}, S_{O N y}\right)$, $S_{O F F}\left(S_{O F F x}, S_{O F F y}\right)$ 라 하고 복원된 신호에 대 한 시작점과 끝점을 각각 $S_{O N}^{\prime}\left(S_{O N x}^{\prime}, S_{O N y}^{\prime}\right)$, $S_{O F F}^{\prime}\left(S_{O F F x}^{\prime}, S_{O F F y}^{\prime}\right)$, 원 신호의 극점을 $P\left(P_{x}, P_{y}\right)$ 로 했을 때 위치 $(L)$, 길이 $(l)$. 진폭 $(A)$ 에 대한 왜곡율은 다음과 같이 계산한다.

$$
\begin{gathered}
L=\left|\sqrt{\left(S_{\text {ONx }}^{\prime}-S_{\text {ONx }}\right)^{2}+\left(S_{\text {ONy }}^{\prime}-S_{\text {ONy }}\right)^{2}}\right| \\
l=\left|\sqrt{\left(S_{\text {OFFx }}-S_{\text {ONx }}\right)^{2}}-\sqrt{\left(S_{\text {OFFx }}^{\prime}-S_{\text {ONx }}^{\prime}\right)^{2}}\right| \\
A=\left|P_{y}-\left(\left|S_{\text {OFFy }}-S_{\text {ONy }}\right|\right)\right|
\end{gathered}
$$




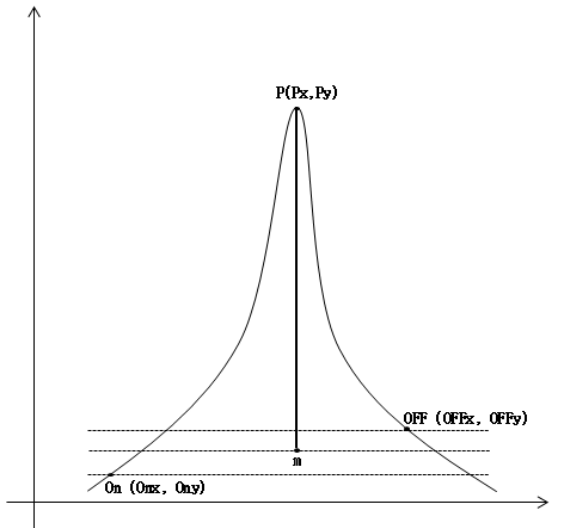

그림 4. 파형의 진폭

Fig. 4. Amolitude of Waveform

각 파형의 형태에 대한 왜곡 계산을 위해 파형의 시작점을 $A\left(A_{x}, A_{y}\right)$, 극점을 $B\left(B_{x}, B_{y}\right)$ 라 하고 $A$ 와 $B$ 사이 파형 위를 움직이는 점을 $C\left(C_{x}, C_{y}\right)$ 라 한다. $A$ 와 $B$ 사이를 잇는 직전에서 수직으로 $C$ 점 사이의 거리 $d$ 를 계산하면 다음과 같다.

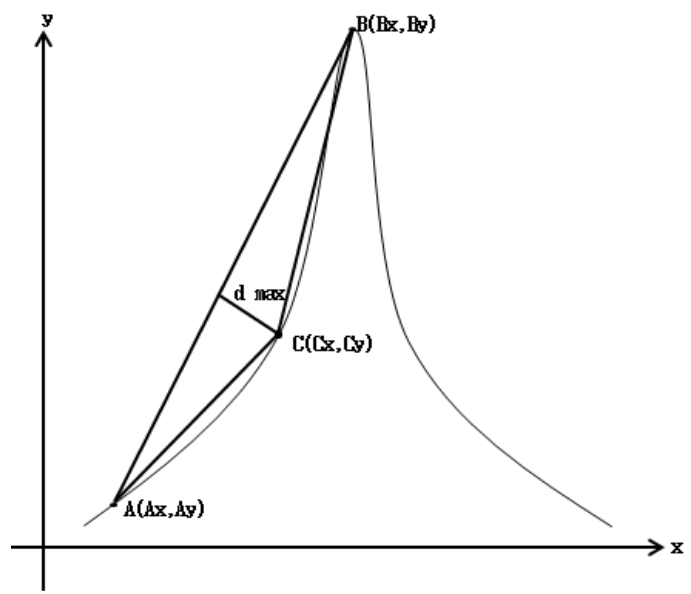

그림 5. 파형의 형태

Fig. 5. Waveform Shape

이 때 최대 거리 $d_{\mathrm{max}}$ 를 선택하고 직선 $\overline{A B}$ 에 대해 신호가 안쪽으로 휜 경우 $d$ 값을 + , 바깥쪽으 로 휜 경우 $d$ 값을 -로 한다. 끝으로 원 신호와 복 원된 신호의 $d_{\mathrm{max}}$ 값을 비교하여 파형의 형태에 대 한 왜곡 율을 계산할 수 있다. 정점에서부터 끝점까 지의 왜곡 율도 동일하게 적용한다.

파형과 파형사이의 거리 간격 계산을 위해선 신호의 극점을 이용한다. 현재의 $\mathrm{R}$ 파 극점을 $R\left(R_{x}, R_{y}\right)$, 다음 $\mathrm{R}$ 파 극점을 $R^{\prime}\left(R^{\prime} x, R^{\prime} y\right), \mathrm{Q}$ 파, $\mathrm{T}$ 파, $\mathrm{P}$ 파의 극점을 각각 $Q(Q x, Q y)$, $T(T x, T y), P(P x, P y)$ 라 했을 때 R-R 간격
$(R I), \mathrm{Q}-\mathrm{T}$ 간격 $(Q T I), \mathrm{P}-\mathrm{R}$ 간격 $(P R I)$ 은 다음과 같다.

$$
\begin{aligned}
& R I=\left|\sqrt{\left(R^{\prime} x-R x\right)^{2}+\left(R^{\prime} y-R y\right)^{2}}\right| \\
& Q T I=\left|\sqrt{(T x-Q x)^{2}+(T y-Q y)^{2}}\right| \\
& P R I=\left|\sqrt{(R x-P x)^{2}+(R y-P y)^{2}}\right|
\end{aligned}
$$

마지막으로 $\mathrm{P}$ 파, $\mathrm{QRS}$ 군, $\mathrm{T}$ 파와 3가지 간격에 대 한 왜곡율은 전체 심전도 신호에 대한 PQRST파를 하나의 단위 $(n)$ 로 두고 계산범위 $(N)$ 를 계산한다.

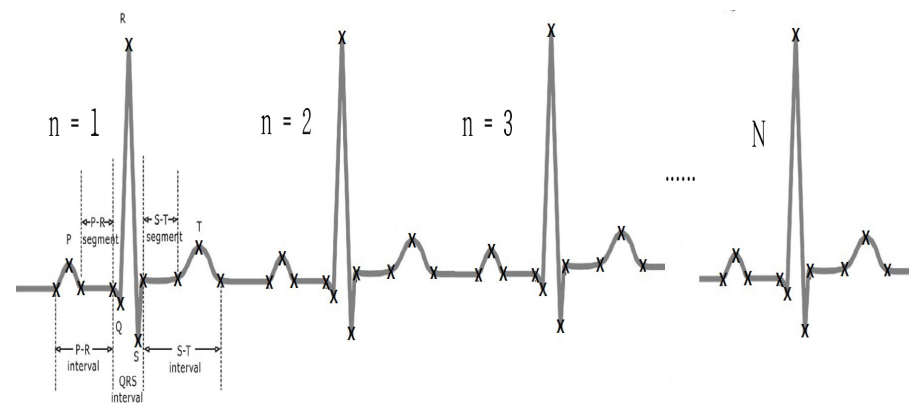

그림 6. 심전도 파형 구분

Fig. 6. ECG Signal Segments

$$
\begin{aligned}
& L_{D R}= \frac{\sum_{n=1}^{N}(L(n)-\tilde{L}(n))}{\sum_{n=1}^{N} L(n)} \times 100 \\
& l_{D R}=\frac{\sum_{n=1}^{N}(l(n)-\tilde{l}(n))}{\sum_{n=1}^{N} l(n)} \times 100 \\
& P_{D R}=\frac{\sum_{n=1}^{N}(P(n)-\tilde{P}(n))}{\sum_{n=1}^{N} P(n)} \times 100 \\
& \sum_{D R}=\frac{\sum_{n=1}^{N}(d(n)-\tilde{d}(n))}{\sum_{n=1}^{N} d(n)} \times 100
\end{aligned}
$$




$$
\begin{gathered}
R I_{D R}=\frac{\sum_{n=2}^{N}(R I(n)-\widetilde{R} I(n))}{\sum_{n=2}^{N} R I(n)} \times 100 \\
Q T I_{D R}=\frac{\sum_{n=1}^{N}(\operatorname{QTI}(n)-\widetilde{Q T} I(n))}{\sum_{n=1}^{N} \operatorname{QTI}(n)} \times 100 \\
P R I_{D R}=\frac{\sum_{n=1}^{N}(\operatorname{PRI}(n)-\widetilde{P R} I(n))}{\sum_{n=1}^{N} \operatorname{PRI}(n)} \times 100
\end{gathered}
$$

\section{III. 실험환경 및 결과}

본 논문에서는 제안한 방법을 검증하기 위하여 MIT-BIH 부정맥 데이터베이스 레코드 $100 \mathrm{MLI}$ 신호의 샘플링 데이터를 사용하여 실험하였다. MIT-BIH 부정맥 데이터베이스는 심전도 신호처리 에 널리 이용되고 있는 임상데이터로 샘플링 주파 수는 $360 \mathrm{~Hz}$ 로 심검자로부터 약 30 분 동안 측정한 것이다. MATLAB을 사용하여 표본화하여 나타내었 다.

일반적으로 심전도 신호는 약 $0.05 \sim 100 \mathrm{~Hz}$ 의 주파수 대역을 가지면서, 내부 및 외부 요인들에 의 한 다양한 잡음 성분들이 포함되어 있다. 심전도 신 호만을 추출하기 위한 전처리 과정으로써 보통 1 $25 \mathrm{~Hz}$ 의 대역통과필터(Band Pass Filter)를 한다.

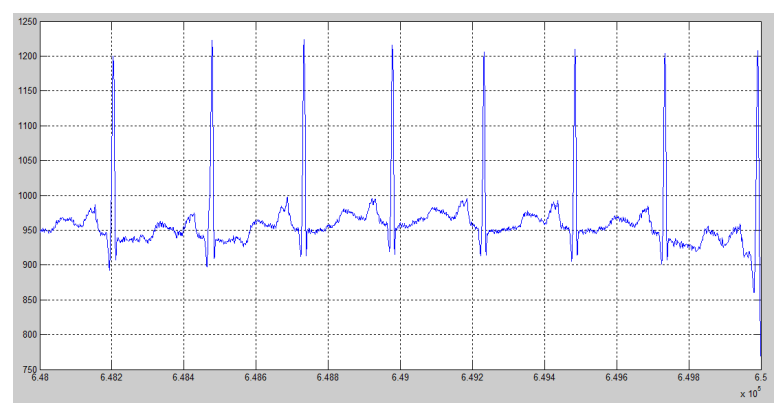

그림 7. 심전도 원 신호

Fig. 7. Original ECG Signal

그림 7은 심전도 신호를 대역통과 필터에 통과시 켜 노이즈를 제거한 신호 $(C(t))$ 이다. 이 신호에 가 우시안 함수의 변수 $\sigma$ 값을 조정하여 필요한 정점만
을 추출할 수 있고 이러한 정점은 각 파형의 시작 과 끝, 극점이 된다.

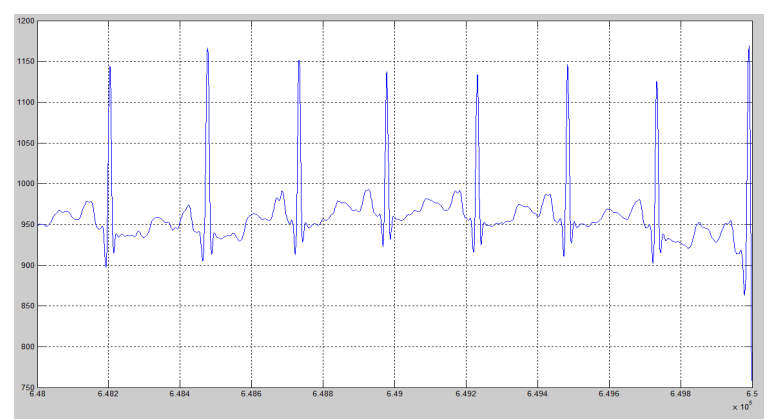

그림 8. 가우시안 함수를 적용한 신호

Fig. 8. Gaussian function applied Signal

그림 8은 신호 $C(t)$ 에 가우시안 함수를 적용한 신호를 보여준다. 분석을 위해 실시간 심전도 전처 리용으로 개발된 AZTEC 알고리즘을 이용하여 신 호를 압축 후 다시 복원하면 아래 그림과 같은 신 호가 나타난다.

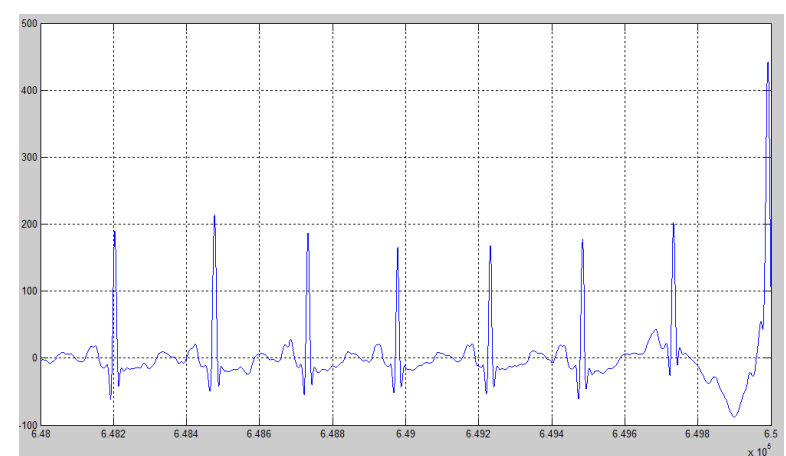

그림 9. 압축 후 복원된 신호

Fig. 9. Restored Signal after Compression

제안하는 심전도 압축알고리즘에 대한 성능평가 는 아래 표와 같이 나타난다.

표 3. 압축알고리즘에 대한 파형의 왜곡

Table. 3. Distortion of Waveform for Compression Algorithm

\begin{tabular}{|c|c|c|c|}
\hline & $\mathrm{P}$ 파 & $\mathrm{QRS}$ 군 & $\mathrm{T}$ 파 \\
\hline 위치 $(L)$ & $7.5 \%$ & $8.6 \%$ & $6.6 \%$ \\
\hline 길이 $(l)$ & $5.6 \%$ & $7.3 \%$ & $4.6 \%$ \\
\hline 진폭 $(A)$ & $9.6 \%$ & $9.5 \%$ & $11.5 \%$ \\
\hline 형태 $(d)$ & $16.6 \%$ & $17.5 \%$ & $15.5 \%$ \\
\hline
\end{tabular}


표 4. 압축알고리즘에 대한 거리오차

Table. 4. Distance error for Compression Algorithm

\begin{tabular}{|c|c|c|c|}
\hline & $\mathrm{P}$ 파 & $\mathrm{QRS}$ 군 & $\mathrm{T}$ 파 \\
\hline 왜곡율 & $17.6 \%$ & $9.5 \%$ & $10.6 \%$ \\
\hline
\end{tabular}

위의 결과에서 AZTEC 압축 알고리즘은 대체적 으로 신뢰도가 높은 것으로 나타나지만 세부적인 사항을 볼 때 각 파형의 형태는 다른 요소에 비해 왜곡율이 높게 나타난다. 특히 QRS군의 형태가 $17.5 \%$ 로 가장 왜곡율이 높은 것을 알 수 있다. 이 는 AZTEC 알고리즘은 신호의 차이에 대한 압축을 실행하고, 그 특성상 주파수 변화가 적은 구역에 대 해 좋은 압축률을 보이지만 $\mathrm{QRS}$ 군 같은 주파수 변 화가 큰 구간에서는 많은 오차를 나타내기 때문으 로 생각된다. 파형간의 간격은 R-R 간격이 $17.6 \%$ 로 가장 왜곡율이 가장 높은 것을 확인할 수 있고 Q-T 간격은 $9.5 \%$ 로 상대적으로 압축에 의한 왜곡 을 덜 받는 것을 알 수 있다.

제안하는 심전도 압축 알고리즘에 대한 성능평가 의 결과는 평균 $10.5 \%$ 로 기존의 PRD 수치보다 대 체로 작은 값을 보이고 있는데 이것은 성능에 대한 평가가 진단에 필요한 6가지 요소에만 범위를 두고, 그 외의 신호는 왜곡율을 무시하기 때문으로 생각 된다.

\section{IV. 결 론}

본 논문에서는 심전도 신호의 PQRST파를 기준 으로 신호의 압축에 대한 진단자의 관점에서 새로 운 성능평가를 제시하였다.

기존의 압축 알고리즘이 수학적인 신호의 왜곡율 을 계산하여 그 성능을 평가하였다면 제안하는 심 전도 압축에 대한 성능 평가는 진단에 필요한 6 가 지 요소들에 대한 진단자의 관점에서 성능을 평가 하도록 한다. 가우시안 함수를 이용하여 신호의 평 활 화 단계를 거쳐 곡선에 따른 거리의 변화율을 이용하여 $\mathrm{PQRST}$ 파형의 시작점과 끝점, 극점을 찾 아내 원 신호와 압축 후 복원된 신호간의 6가지 요 소에 대한 왜곡 율을 계산하여 압축에 대한 성능을 평가하였다.

이러한 성능평가는 기존의 성능평가에서는 확인 할 수 없는 각각 주요 파형에 대한 세부적인 오차 의 확인이 가능하다. 앞의 실험에서 확인했듯이 AZTEC 압축 알고리즘 같은 경우 PRD의 수치만으
로는 각 파형에 대한 오차는 알 수 없지만 제안하 는 압축의 성능평가에 의해 $\mathrm{P}$ 파는 평균 $9.8 \%, \mathrm{QRS}$ 군은 평균 $10.725 \%, \mathrm{~T}$ 파는 평균 $9.55 \%$ 의 오차율을 가지고 주파수가 큰 $\mathrm{QRS}$ 군의 오차가 큰 것을 확인 할 수 있다. 이를 통해 AZTEC의 취약점을 확인할 수 있다. 다른 압축 알고리즘 역시 이러한 세부적 오차확인을 통해 심전도 진단에 중요한 참고자료가 될 수 있다.

\section{참 고 문 헌}

[1] Dale Davis. "Quick and Accurate 12-Lead ECG Interpretation", 군자, pp.55-66

[2] S.-j. Lee and M. Lee, "A real-time ECG data compression algorithm for a digital Holter system," in Proc. IEEE 30th Annu. Int. Conf. Eng. Med. Biol. Soc., Aug. 20-25, 2008, pp. 4736-4739.

[3] Y. Zigel, A. Cohen, and A. Katz, "ECG signal compression using analysis by synthesis coding," IEEE Trans. Biomed. Eng., vol. 47, no. 10, pp. 1308-1316, Oct. 2000.

[4] Kim, H., R. F. Yazicioglu, et al, "ECG signal compression and classification algorithm with quad level vector for ECG holter system Information Technology in Biomedicine," IEEE Transactions on 14(1): 93-100, 2010.

[5] B. Furht and A.Perez, "AN adaptive real-time ECG compression algorithm with variable threshold," IEEE Trans. Biomed. Eng., vol. 35, pp. 489-494, June 1988.

[6] R. C. Barr, S. M. Blanchard, and D. A. Dipersio, "SAPA-2 is the Fan," IEEE Trans. Biomed. Eng., vol. BME-32, no. 5, pp. 337, May 1985.

[7] M. E. Womble, J. S. Halliday, S. K. Mitter, M. C. Lancaster, J. H. Triebwasser, "Data Compression for Storing and Transmitting ECG's / VCG's", Proceedings of the IEEE, Vol. 65, N5, May 1977, pp. 703-706.

[8] V. A. Allen, J. Belina J., "ECG data compression using the discrete cosine transform", Proc. of Computers in Cardiology, IEEE Computer Society Press, Silverspring, MD, 1992, pp. 687-690.

[9] Z. Lu., D. Y. Kim, and W. A. Pearlman, 
"Wavelet compression of ECG signals by the set partitioning in hierarchical trees algorithm," IEEE Transactions on Biomedical Engineering, vol.47, no.7, pp. 849-856, July 2000.

[10] Sang-il Ko, Jong-suk Choi and Byoung-hoon Kim, A. G. Ramakrishnan and S. Saha, "ECG coding by wavelet-based linear prediction," IEEE Trans. Biomed. Eng., vol. 44, pp. 394-402, May 1997.

[11] Han MS, Ahn HM, Lee JM, Kim YK, "A Study on Hybrid ECG Compression Algorithm Using Templetes and AZTEC," 대 한의료정보학회지, 제6권, 제3호, vol. 6, no. 3.2000 .

[12] Tae-Hun Kim, Sung-Wan Kim, Chun-Ha Ryu, Byoung-Ju Yun, jeong-Hong Kim, Byung-Jae Choi and Kil-Houm Park, "ECG Signal Compression usting Feature Point based on Curvature" 한국지능시스템학회 논 문지, vol. 20, no. 5, pp. 624-630, 2010.

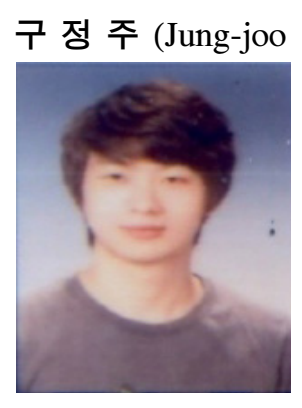

준회원

2010년 8 조선대학교 정보 통신공학과 공학사

2010년 2월 현재 조선대학교 정보통신 공학과 석사과정

<관심분야> 임베디드 시스템 개발, AVR, FPGA MSP430, ECG

최 광 석 (Goang-seog Choi)

준회원

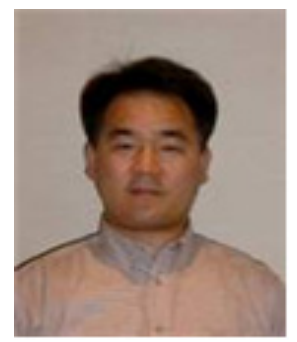

1987년 2월 부산대학교 전자 공학과 공학사

1989년 2월 부산대학교 전자 공학과 공학석사

2002년 2월 고려대학교 전자 공학과 공학박사

1989년 1월 2006년 2월 삼성

전자 디지털미디어 연구소 수석연구원

2006년 3월 현재 조선대학교 정보통신공학과 조교수 <관심분야> 임베디드 시스템 개발, 디지털 미디어 용 ASIC/SOC 설계, 채널 부호 